Tobias Schripp, Friederike Herrmann, Patrick Oßwald, Markus Köhler, Alexander Zschocke, David Weigelt, Michael Mroch, Christian Werner-Spatz, Particle Emissions of two Unblended Alternative Jet Fuels in a Full Scale Jet Engine, Fuel 256 (2019) 115903.

The original publication is available at https://www.sciencedirect.com/science/article/pii/S0016236119312554

http://dx.doi.org/10.1016/j.fuel.2019.115903

(C) <2019>. This manuscript version is made available under the CC-BY-NC-ND 4.0 license http://creativecommons.org/licenses/by-nc-nd/4.0/ 


\section{Particle Emissions of two Unblended Alternative Jet Fuels in a Full Scale Jet Engine}

T. Schripp ${ }^{1, *}$, F. Herrmann ${ }^{1}$, P. Oßwald ${ }^{1}$, M. Köhler ${ }^{1}$, A. Zschocke ${ }^{2}$, D. Weigelt ${ }^{3}$, M. Mroch ${ }^{3}$ and C. Werner-Spatz ${ }^{3}$

${ }^{1}$ Institute of Combustion Technology, German Aerospace Center, Stuttgart, 70569, Germany

${ }^{2}$ Deutsche Lufthansa AG, Köln, 50679, Germany

${ }^{3}$ Deutsche Lufthansa Technik AG, Hamburg, 22335, Germany

* corresponding author (tobias.schripp@dlr.de)

\section{Abstract}

The emission of soot particles from aircraft jet engines is relevant due to their impact on contrail formation and local air quality in airport areas. The reduction of particle emission may be achieved by changes in jet engine design. This, however, will only affect new aircraft. Previous studies have shown that the use of alternative jet fuels feature a co-beneficial reduction of soot emission beside an improved carbon footprint. In the present study, a CFM56-5C4 engine was operated on a test rig with three different fuel types: one reference kerosene, a catalytic hydrothermolysis jet fuel (Readijet) and an unblended alcohol-to-jet (ATJ) fuel. Due to the absence of aromatics in the ATJ fuel, ASTM jet fuel requirements are not met, but the use of this fuel led to a reduction of $70 \%$ in particle mass compared to the reference fuel. The ReadiJet fuel has higher aromatic content, lower fuel hydrogen content and, thus, an increase in particle emission was observed. For the present engine, the highest soot reductions were observed at lower power settings. In accordance to previous studies, the soot emission showed a good correlation to the hydrogen content of the fuels and the emission reduction matches the estimations of the imFOX model. In order to compare test rig studies to field studies, transient processes must be considered because they govern takeoff conditions. Four experiments with different transient thrust patterns were performed on the test rig with regular Jet $A-1$. If the thrust changes were not very rapid (e.g. $5 \mathrm{~s}$ to $\sim 90 \%$ thrust) the results could be reproduced with a set of pseudo-stationary processes to a sufficient extend. This emphasizes the relevance of test-rig studies for real in-field measurements and local air quality studies. 
Keywords: biofuels; kerosene; aircraft exhaust; soot emission; transient operation

\section{Introduction}

The release of fine and ultra-fine particles from aircraft engines is subject of many scientific studies due to its possible impact on the upper atmosphere [1] and on the local air quality in airport areas [2]. Understanding the impact of fuel and engine operation parameters on the soot formation in aircraft engine exhaust is a vital aspect in emissions reduction [3], contrail mitigation [4], and fuel design. Unveiling the connections between these parameters requires lab experiments, modeling studies, but also sophisticated field studies. Experimental studies revealed that the hydrogen content of the fuel is an adequate indicator for soot emission in aviation [5-8]. Some alternative jet fuels feature higher hydrogen content than regular Jet A-1 due to their lower amount of aromatics. Among these, Fischer-Tropsch (FT) and Hydrotreated Esters and Fatty Acids (HEFA) fuels or their respective fuel blends are most common. Pure FT and HEFA fuels do not meet current ASTM requirements with regard to aromatic content and show insufficient seal swell behavior [9]. At the current state (2019), ASTM D7566 allows 50\% HEFA in conventional jet fuel. FT blends have been experimentally tested on a CFM56-2C engine in the AAFEX-I and AAFEX-II campaigns [6, 10], while HEFA blends have been tested in the ACCESS [3] and ECLIF [7] campaigns. These campaigns illustrated that significant reduction in particle mass and particle number can be achieved with alternative jet fuel blends under real conditions. Fuel blends that do not meet ASTM criteria have been tested in lab-scale or test rigs. Lobo et al. [11] applied an aromatics-free Fischer-Tropsch (FT) fuel in a CFM56-7B engine and reported a reduction of $62 \%$ for PM emission for the whole landing and take-off (LTO) cycle in contrast to regular Jet A-1 (18.5 vol\% aromatics). Zheng et al. [12] tested 16 different fuel blends in a gas turbine combustor with the hydrogen content ranging from $13.4 \mathrm{~m} \%$ to $15.5 \mathrm{~m} \%$. They observed a reduction up to $80 \%$ in the PM emissions compared to their reference kerosene $(13.9 \mathrm{~m} \% \mathrm{H})$. A higher reduction $(\geq 90 \%)$ in PM emission could be observed when testing a FT-fuel $(15.4 \mathrm{~m} \% \mathrm{H})$ in comparison to a regular Jet $\mathrm{A}-1(13.7 \mathrm{~m} \% \mathrm{H})$ on a small turbofan engine [13]. 
Transferring the results of such fuel variation studies in test-rigs and ground measurements to the real application case is often complicated by the fact that emission during transient processes is not considered. This approach is reasonable, since the number of parameters that are changing in the engine during transient events is vast and the parameters are impacted by external influences (e.g. inlet temperature). However, transient processes are of significant relevance for ground level emission and the impact on the local air quality of airports. In 2014, Moore et al. [14] recorded 275 exhaust take-off plumes at Los Angeles Airport. The data set illustrates the variety of jet engine exhaust emission under real world conditions. For example, 19 plumes of CFM56-5B engines were recorded on the same day $(5 / 25 / 14)$. Presuming that the same fuel was applied, the spread in emission indices for black carbon $(120-582 \mathrm{mg} / \mathrm{kg})$ and non-volatile particle number $\left(0.6-7.0 \# 10^{15} / \mathrm{kg}\right)$ may be attributed to the different age and status of the engines. It is of interest, if the emission from such transient processes can be described by a series of stationary processes at an acceptable margin of error. It should be noted that the results are limited to the engine type used in this study and cannot necessarily be transferred to other engine designs.

In this study, a test cell setup was chosen due to the well-defined boundary conditions, making it ideal for fuel test variations. The present study reports the results of two experiments on a CFM56-5C4 jet engine (a variant of the CFM56 engine used on A340 aircraft) at a test rig of Lufthansa Technik in Hamburg. In the first experiment, the engine was operated with three different fuels at seven different power settings ranging from idle to takeoff conditions. Among the three fuels, one non-certified fully-synthetic jet fuel was used. In the second experiment, four additional runs were performed with regular Jet A-1 to further assess the impact of different patterns of transient processes on the emission of the engine. The measurements were not performed at the engine exit plane as described in ICAO Annex 16 [15] but at a distance of approx. $25 \mathrm{~m}$ behind the engine. This approach was selected since the aged aerosol provides more insight into the impact on the local air quality. 


\section{Materials and Methods}

This study used the "Engine for Validation Experiments" (EVE) at the Lufthansa Technik test cell in Hamburg. This system is a regular CFM56-5C4 engine (max. thrust $151.3 \mathrm{kN}$ ) that has been withdrawn from operational service and instrumented to be used as a test vehicle. Thus, the engine can be operated on ASTM non-compliant fuels. The engine was operated with three different fuels (Table 1) at different speed levels ranging from $~ 900$ RPM $(20 \%$, "ground idle") to $~ 4500$ RPM (96\%, "take off"). In the test cell, the engine exhaust is directed into a flow tunnel, which was equipped with a stainless-steel probe for sampling near to the center of the air stream (see Figure SI1). From the flow tunnel, the air was pumped through a $25 \mathrm{~m}$ heated tube (ID $6 \mathrm{~mm}, 75^{\circ} \mathrm{C}$ ) to the measuring instruments at a flow rate of $6 \mathrm{~L} / \mathrm{min}$. The flow was achieved with two parallel DEKATI DI-1000 diluters (see Figure SI1).

The fuels applied in this study vary in feedstock and chemical composition. The Alcohol-toJet Synthesized Paraffinic Kerosene (ATJ-SPK, Gevo) does not contain aromatic compounds. In contrast, ReadiJet (ARA) fuel features a much higher aromatic content than the chosen reference Jet A-1. ReadiJet is produced in the Catalytic Hydrothermolysis $(\mathrm{CH})$ process (also called HEFA-SKA or BIC process [16]) from waste oils and fats. The $\mathrm{CH}$ process is designed to reproduce the molecular composition of crude oil based jet fuels. The listed fuel parameters (Table 1) were determined by an accredited test lab according to the respective testing standards. Due to the relevance of the hydrogen content for data interpretation, the parameter was determined via the combustion method (ASTM D5291) and via nuclear magnetic resonance relaxometry (ASTM D7171). Fuel chromatograms (GCxGC) and the full distillation curve are available in the Supporting Information. 
Table 1: Fuel properties of the reference kerosene and the two biofuels.

\begin{tabular}{|c|c|c|c|c|}
\hline Manufacturer & unknown & ARA & Gevo & \\
\hline Feedstock & crude oil & oils and fats & $\begin{array}{r}\text { linear or } \\
\text { branched } \\
\text { alcohols }\end{array}$ & \\
\hline Aromatic content [vol\%] & 15.6 & 20.9 & $<1$ & ASTM D6379 \\
\hline Carbon content [m\%] & 85.9 & 86.1 & 84.1 & ASTM D5291 \\
\hline \multirow[t]{2}{*}{ Hydrogen content [m\%] } & 14.1 & 13.7 & 15.5 & ASTM D5291 \\
\hline & $13.98 \pm 0.02$ & $13.60 \pm 0.07$ & $15.31 \pm 0.03$ & ASTM D7171 ${ }^{\mathrm{a})}$ \\
\hline Heat of Combustion [MJ/kg] & 43.07 & 42.62 & 43.89 & ASTM D240 \\
\hline Density $\left(15^{\circ} \mathrm{C}\right)\left[\mathrm{g} / \mathrm{cm}^{3}\right]$ & 0.8008 & 0.8052 & 0.7673 & ASTM D4052 \\
\hline Smoke point [mm] & 23.1 & 20.2 & 27 & ASTM D1322 \\
\hline Sulfur content [m\%] & $<0.001$ & $<0.001$ & $<0.001$ & DIN EN ISO 14596 \\
\hline \multicolumn{5}{|l|}{ Distilliation Curve $\left[{ }^{\circ} \mathrm{C}\right]$} \\
\hline IBP & 165.3 & 171.9 & 174.8 & ASTM D86 \\
\hline $10 \%$ recovered & 175.0 & 186.1 & 180.9 & ASTM D86 \\
\hline $50 \%$ recovered & 201.4 & 204.7 & 187.4 & ASTM D86 \\
\hline $90 \%$ recovered & 241.2 & 239.6 & 236.2 & ASTM D86 \\
\hline FBP & 255.4 & 251.5 & 263.1 & ASTM D86 \\
\hline Flash Point $\left[{ }^{\circ} \mathrm{C}\right]$ & 48 & 66 & 47 & ASTM D56 \\
\hline JFTOT Pressure Drop [Torr] & - & $2.0\left(280^{\circ} \mathrm{C}\right)$ & $0.0\left(325^{\circ} \mathrm{C}\right)$ & ASTM D3241 \\
\hline JFTOT Deposit Rating & - & $<1\left(280^{\circ} \mathrm{C}\right)$ & $<1\left(325^{\circ} \mathrm{C}\right)$ & ASTM D3241 \\
\hline Existent gum [mg / $100 \mathrm{~mL}]$ & $<1$ & $<1$ & 2.2 & ASTM D381 \\
\hline Viscosity, $-20^{\circ} \mathrm{C}\left[\mathrm{mm}^{2} / \mathrm{s}\right]$ & 4.147 & 4.754 & 4.779 & ASTM D445 \\
\hline Viscosity, $-40^{\circ} \mathrm{C}\left[\mathrm{mm}^{2} / \mathrm{s}\right]$ & - & 9.200 & 9.037 & ASTM D445 \\
\hline Surface tension $[\mathrm{mN} / \mathrm{m}], 10^{\circ} \mathrm{C}$ & $26.00 \pm 0.04$ & $27.00 \pm 0.20$ & $24.00 \pm 0.04$ & DIN EN 14370 \\
\hline Surface tension $[\mathrm{mN} / \mathrm{m}], 40^{\circ} \mathrm{C}$ & $23.00 \pm 0.40$ & $24.00 \pm 0.05$ & $21.00 \pm 0.04$ & DIN EN 14370 \\
\hline
\end{tabular}

a) error: standard deviation from three samples

The combustion gases (e.g. $\mathrm{CO}_{2}, \mathrm{CO}, \mathrm{NO}_{x}$ ) were monitored with a FT-IR Multigas Analyzer 2030 (MKS). The particle counters were equipped with a DEKATI DI-1000 diluter in order to prevent overloading. The dilution was performed with nitrogen (purity $99.999 \mathrm{v} \%$ ). The dilution factor (7.7) was determined on the basis of a carbon dioxide measurement with and without DEKATI diluter. Dynamics of particle release were monitored with an Engine Exhaust Particle Sizer (EEPS, TSI Inc.) that measures the particle size distribution between 5.6 and $560 \mathrm{~nm}$ simultaneously in 32 channels at $10 \mathrm{~Hz}$ (the lowest 25 channels were used for analysis, see Results section for more details). The EEPS data was processed with the "soot" inversion matrix. The particle number concentration was additionally monitored at $1 \mathrm{~Hz}$ with a 3776 Condensation Particle Counter (CPC, TSI Inc.) that covers particles from $2.5 \mathrm{~nm}$ to $3 \mu \mathrm{m}$. The size distribution of particles was further measured with a Scanning Mobility 
Particle Sizer (SMPS, TSI Inc.) consisting of a 3080 Classifier, a 3081 Long DMA, a 3088 Advanced Aerosol Neutralizer and a 3022A CPC. The SMPS was operated at a flow rate of 1.5 L/min and covered the particle size range between $10 \mathrm{~nm}$ and $195 \mathrm{~nm}$ in 83 channels. The upscan time was $80 \mathrm{~s}$ with $10 \mathrm{~s}$ retrace. The particle mass was calculated from the EEPS based on the particle size distribution and particle number concentration assuming spherical particles with a density of $1 \mathrm{~g} / \mathrm{cm}^{3}$. It must be noted that - despite the soot inversion matrix of the EEPS - the mass estimation has a high uncertainty because the effective particle density is depending on size and power setting of the engine [17]. The particle number concentration of the size-resolving instruments was corrected for the particle loss function of the sampling setup (see Figure SI2). The particle loss by diffusion was estimated for a laminar flow in a tube [18] $(\operatorname{Re}=1043)$. Gravitational losses were not considered.

Since the relationship between power setting for "idle", "approach", "climb" and "take-off" defined by ICAO and the fan speed (N1) are unique for a specific engine at sea level static conditions and International Standard Atmosphere (ISA) conditions [19], the respective operating conditions of the test engine were specified to match the power settings of a CFM56-5C4 engine based on the fuel flow. The ICAO database [20] specifies emissions for the thrust settings 100\% ("take-off"), $85 \%$ (“climb"), 30\% ("approach") and 7\% ("idle"). The corresponding fuel flows for the CFM56-5C4 engine are summarized in Table 2. Using these values, the corresponding power settings in the present experiment are T/O, M/C2, IP2 and FI. In order to improve readability, the different power settings are not numbered along the engine operating curve but are named in relation to established operating points, such as take-off $(T / O)$, maximum continuous thrust $(M / C)$, ground idle $(\mathrm{Gl})$ and flight idle $(\mathrm{FI})$. The CFM56-5C engine can be purchased in two different thrust ratings (C2 and C4). These options are mirrored in two different M/C and T/O settings. Since T/O C2 has the same fan speed as M/C4, this setting was skipped. A summary of the applied power settings is given in Table 2. Each setting was kept stable for $3 \mathrm{~min}$ ( $5 \mathrm{~min}$ for $\mathrm{FI}$ and $\mathrm{Gl}$ ). Four series were performed on the same day. The reference kerosene was used at the beginning $(\operatorname{Ref}(1))$ and at the end of the experiment $(\operatorname{Ref}(2))$. A table with the full test protocol is given in the 
Supporting Information (Table Sl1). The first power setting after fuel change was not considered for analysis to prevent possible carryover effects. After each reference run, two acceleration experiments ("fast" and "slow") were performed. The runs after $\operatorname{Ref}(1)$ are named $A$ and $C$ while the runs after $\operatorname{Ref}(2)$ are named $B$ and $D$. Details on the different acceleration patterns are shown in the results section.

Table 2: N1 fan speed, thrust and fuel flow at the different engine operating points as recorded by the sensors of the test engine. The uncertainty is calculated over the whole duration of the power setting.

\begin{tabular}{|l|c|c|c|c|c|}
\hline \multirow{2}{*}{ Operating point } & \multicolumn{2}{|c|}{ N1 speed } & \multicolumn{2}{c|}{ Thrust (measured) } & Fuel flow \\
\cline { 2 - 4 } & {$[\mathbf{R P M}]$} & {$[\%]^{\mathrm{a})}$} & {$[\mathbf{k N}]$} & {$[\%]^{\mathrm{b})}$} & \\
\hline C4 Take-Off (T/O) & $4617 \pm 31$ & $93 \%$ & $133.4 \pm 0.7$ & $88 \%$ & $1.47 \pm 0.02$ \\
\hline C4 Maximum Continuous (M/C4) & $4332 \pm 26$ & $87 \%$ & $119.1 \pm 0.6$ & $79 \%$ & $1.25 \pm 0.02$ \\
\hline C2 Maximum Continuous (M/C2) & $4237 \pm 21$ & $85 \%$ & $112.6 \pm 0.3$ & $74 \%$ & $1.18 \pm 0.01$ \\
\hline Intermediate point 1 (IP1) & $3747 \pm 21$ & $75 \%$ & $82.9 \pm 0.1$ & $55 \%$ & $0.83 \pm 0.01$ \\
\hline Intermediate point 2 (IP2) & $2958 \pm 17$ & $59 \%$ & $47.3 \pm 0.1$ & $31 \%$ & $0.46 \pm 0.01$ \\
\hline Flight Idle (FI) & $1308 \pm 6$ & $26 \%$ & $8.4 \pm 0.1$ & $6 \%$ & $0.12 \pm 0.00$ \\
\hline Ground idle (GI) & $935 \pm 5$ & $19 \%$ & $4.2 \pm 0.1$ & $3 \%$ & $0.09 \pm 0.00$ \\
\hline
\end{tabular}

a) max. 4985 RPM (N1); b) max. $151.3 \mathrm{kN}$

Generally, the environmental conditions during the experiment were fairly stable and had negligible impact on the engine performance parameters: the outdoor air temperature at Fuhlsbüttel airport (inlet temperature) increased from $1.5^{\circ} \mathrm{C}(100 \%$ rel. humidity) in the morning (begin of experiment) to $7^{\circ} \mathrm{C}(90 \%$ rel. humidity) in the evening. This corresponds well with the recorded cell inlet temperature of the engine. The background concentration of PM10 at the airport was $11 \mu \mathrm{g} / \mathrm{m}^{3}$ (daily average, station "Flughafen") for the 03.11.2016. The measured concentrations were not corrected for the background.

The calculation of the emission index for particulate emissions and combustion gases follow the proposed method in Chapter 7 of AIR6241 [21] using the obtained particle number concentration (PN) or particle mass concentration (PM), the measured concentration of carbon dioxide in air $\left(\left[\mathrm{CO}_{2}\right]\right)$, the background carbon dioxide concentration $\left(\left[\mathrm{CO}_{2}\right]_{\mathrm{BG}}\right)$, the atmospheric pressure (p), the molar ratio of hydrogen to carbon in the fuel $(\alpha)$ and the molar masses of carbon $\left(\mathrm{M}_{\mathrm{C}}\right)$ and hydrogen $\left(\mathrm{M}_{\mathrm{H}}\right)$. 


$$
\begin{gathered}
\mathrm{EI}\left[\frac{\#}{\mathrm{~kg}}\right]=\mathrm{PN}\left[\frac{\#}{\mathrm{~cm}^{3}}\right] \cdot 10^{6} \cdot \frac{0.082 \cdot \mathrm{T}[\mathrm{K}]}{\mathrm{p}[\mathrm{atm}]\left(\mathrm{M}_{\mathrm{C}}\left[\frac{\mathrm{g}}{\mathrm{mol}}\right]+\alpha \cdot \mathrm{M}_{\mathrm{H}}\left[\frac{\mathrm{g}}{\mathrm{mol}}\right]\right) \cdot\left(\left[\mathrm{CO}_{2}\right]-\left[\mathrm{CO}_{2}\right]_{\mathrm{BG}}\right)} \\
\mathrm{EI}\left[\frac{\mathrm{mg}}{\mathrm{kg}}\right]=\mathrm{PM}\left[\frac{\mathrm{mg}}{\mathrm{m}^{3}}\right] \cdot \frac{0.082 \cdot \mathrm{T}[\mathrm{K}]}{\mathrm{p}[\mathrm{atm}]\left(\mathrm{M}_{\mathrm{C}}\left[\frac{\mathrm{g}}{\mathrm{mol}}\right]+\alpha \cdot \mathrm{M}_{\mathrm{H}}\left[\frac{\mathrm{g}}{\mathrm{mol}}\right]\right) \cdot\left(\left[\mathrm{CO}_{2}\right]-\left[\mathrm{CO}_{2}\right]_{\mathrm{BG}}\right)}
\end{gathered}
$$

The standard deviation of the emission index is derived from the standard deviations of the particle number concentration and the carbon dioxide concentration.

\section{Results and Discussion}

The test engine was able to reach the respective target values of the operating parameters (e.g. thrust level) for all three fuels. The fuel parameters that mainly affect the spray in the combustion chamber are fuel density, viscosity and surface tension. ReadiJet and the ATJ fuel show similar viscosity but significantly differ in surface tension. When estimating the quality of the spray based on the Weber number (We), however, the highest We is expected for the ARA ReadiJet while the values for the reference kerosene and the ATJ fuel are rather similar. A quantitative assessment is complicated by the superposition of the complex impact of the parameters on the spray formation [22] and the internal controls of the engine. The efficiency of the thrust control is illustrated by the fact that ATJ fuel showed similar thrust as the other two fuels at the same fuel flow even though the chemical composition (Fig. SI2-SI4) and the distillation curve (Fig. SI5) are significantly different.

The variation in parameters that are affected by ambient conditions (e.g. inlet temperature) was small since the environmental conditions were quite stable. The combustor inlet temperature (CIT, see Table SI1) was $140-147^{\circ} \mathrm{C}$ for ground idle conditions and $530-548^{\circ} \mathrm{C}$ for T/O C4 over the whole experiment. Therefore, the release of carbon monoxide and nitrogen oxides per amount of fuel burnt was not significantly different for all tested fuels (Figure 1). The obtained emission indices show a good correlation to the values recorded in the ICAO database for CFM56-5C4 engine. The correlation between CIT and CO or NOx emission is given in Figures SI6 and SI7 respectively. Due to the fact that the Gevo ATJ features a slightly higher (1.9\%) heat of combustion than the reference fuel, the overall 
emission of combustion gases and total fuel consumption can be expected to be lower. However, this difference is within the magnitude of the error margin of fuel flow and gas concentration monitoring. Thus, it could not be resolved in the present experiment. However, this does not exclude a positive impact on the reduction of emissions and fuel consumption at a fleet-wide application level.
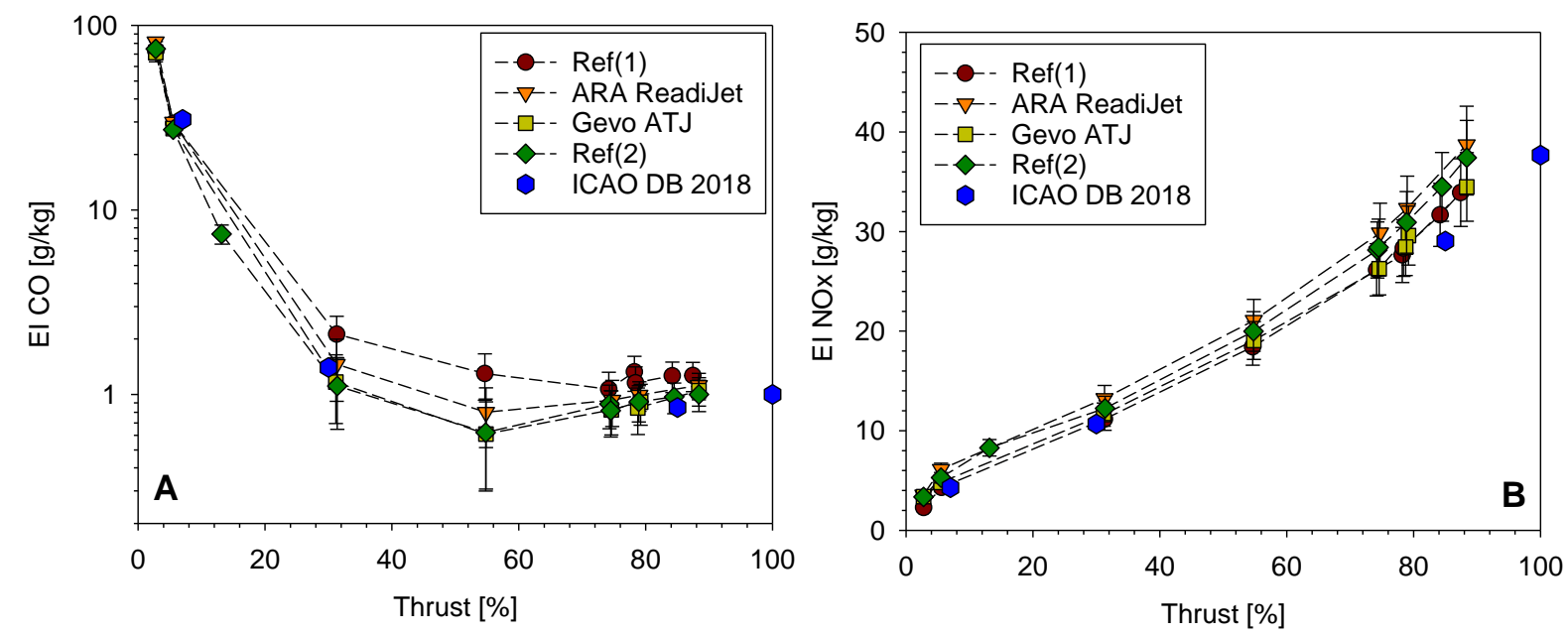

Figure 1: Emission index for carbon monoxide $(A)$ and nitrogen oxides $(B)$ at different fuel flow settings and fuels. Reference values for the CFM56-5C4 engine (blue) were derived from the ICAO database 2018.

\section{Emission of particles}

The determination of the particle number concentration via the Engine Exhaust Particle Sizer was affected by noise in the higher particle size channels $(220-560 \mathrm{~nm})$. While this does not affect the total particle number concentration it had a significant impact on the particle mass concentration. This noise led to deviations between the SMPS and the EEPS at higher emission levels (see Figure SI5). Since the range of the SMPS was limited to $200 \mathrm{~nm}$, the analysis of the EEPS data was also limited to the same range.

At the lowest power settings (ground idle), the particle number emission index shows a high variability (Figure $2 \mathrm{~A}$ ) between the fuels. The determined particle number emission index at ground idle (GI) spans a full order of magnitude between $3 \cdot 10^{14} \# / \mathrm{kg}$ (ATJ) and $4 \cdot 10^{15}$ \#/kg (ReadiJet). More important, the particle number emission of ARA ReadiJet is higher than the 
reference kerosene at $\mathrm{GI}$ but lower at $\mathrm{FI}$ conditions (see Figure $2 \mathrm{~A}$ and SI10). ReadiJet shows this deviation - which was detected by all particle counters - even though the operational parameters (thrust, fuel flow, CIT, etc.) were similar to the other fuels. The deviation is caused by a different release of particles $<20 \mathrm{~nm}$ (Figure 3). The reason for this deviation cannot be explained from the available information. Overall, a change in the particle size distribution due to fuel variation is not expected since the fuel composition should affect the particle formation rate but not the particle growth and formation mechanism [23]. With the exception of ATJ (Figure 3), all tested fuels feature a distinctive particle mode at approx. $10 \mathrm{~nm}$ at idle conditions. With increasing engine thrust, this nucleation mode shifts to the larger accumulation mode. This nucleation mode is not expected to be present at the engine exhaust plane and is expected to consist of volatile particles. Typically, it may be attributed to the sulfur content under sufficient aerosol aging conditions [24]. In the present case, the synthetic fuels are free of sulfur. Thus, other fuel composition parameters govern the emitted number of particles [6]. For power settings above FI and Gl conditions, the particle number emission index of the reference kerosene and ReadiJet do not change substantially, while the corresponding particle mass emission index shows a linear increase with increasing engine power. This change is governed by a shift to larger particles in the particle number size distribution from lower to higher power settings. The development of the particle number and particle mass emission of ATJ differs from the other fuels. For power settings above idle, the particle number emission index for ATJ increases with increasing power while the increase in the particle mass emission index is less linear. ATJ always features the lowest particle emission indices in the experiment.

The ATJ fuel is of the synthesized-isoparaffinic-kerosene-type and mainly consists of a few different branched aliphatic compounds (primarily iso- $\mathrm{C}_{12} \mathrm{H}_{26}$ and iso- $\mathrm{C}_{16} \mathrm{H}_{34}$, see Figure SI4). In contrast to cyclic aromatic systems that already contain the necessary basic structure for soot precursers, linear or branched alkanes feature a lower sooting tendency. Roughly, the sooting tendency of hydrocarbons may be classified as follows: aromatics >> cycloalkanes >> iso-alkanes > n-alkanes. Therefore, the tested ATJ fuel nearly represents the lowest 
technically achievable source for soot emission in the field of jet fuels. Similar properties are expected for farnesane $\left(\mathrm{C}_{15} \mathrm{H}_{32}\right)$, which produces very low amounts of soot precursors during combustion [25] and is allowed to be added to regular Jet A-1 up to $10 \%$. ATJ is currently (2019) allowed to be added up to $30 \%$ [26] but it can be expected that this limit will increase soon. In contrast to the ATJ fuel, aromates and cycloparaffins are preserved during the production process of ReadiJet [16]. As mentioned above, the cyclic structures are a better source for soot precursors, which leads - in addition to the aromatics - to a much higher emission of soot compared to the other fuels tested. Overall, the particle mass emission index shows the expected good correlation to the hydrogen content of the fuels (Figure 4).
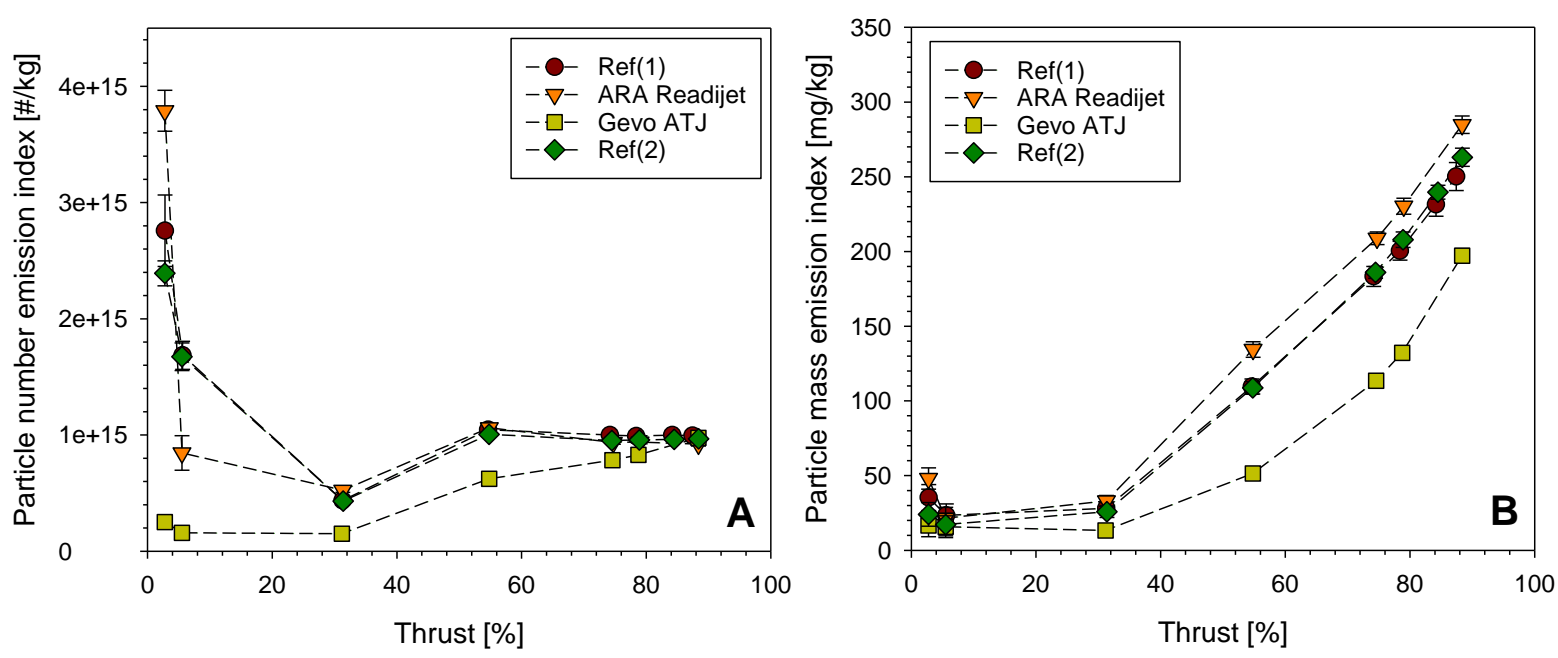

Figure 2: Total particle number $(A)$ and particle mass $(B)$ emission index for the different thrust settings and fuels (EEPS, $5.6-200 \mathrm{~nm}$ ).

It must be noted that the impact of the fuel composition on the particle reduction potential is strongly depending on the jet engine used. Chan et al. [27] used a GE CF-700-2D-2 turbofan engine $(20 \mathrm{kN})$ for testing the emissions from three different alternative fuels in comparison to regular Jet A-1. Their fuels "CH-SKA" and "FT-SPK" are chemically comparable to the ReadiJet and ATJ fuels of this experiment. However, the aromatic content of the CH-SKA differs considerably (17 vol\%). While the observed particle number emission index of the reference Jet A-1 (18.3 vol\% aromatics) match the findings in this paper, the particle number 
reduction potential is: $7-25 \%$ for " $\mathrm{CH}-\mathrm{SKA}$ " and $70-95 \%$ for "FT-SPK". The latter reduction is also observed on the same level for the particle mass emission. This observation is considerably higher than for the CFM56-5C4-engine used in this study. Lobo et al. [11] used similar fuels on a CFM56-7B engine in a test cell setup. For their $100 \%$ FT-fuel $(<0.2$ vol\% aromatics, $15.41 \mathrm{~m} \% \mathrm{H}$ ) they observed a particle number reduction of $52 \%$ and a particle mass reduction of $62 \%$ for the full LTO test cycle. Similar to the present findings, the particle number reduction potential decreases with increasing power setting, while a considerable particle mass reduction is given even for the highest power setting (approx. 60\% for " $100 \%$ FT" fuel and $100 \%$ thrust). 

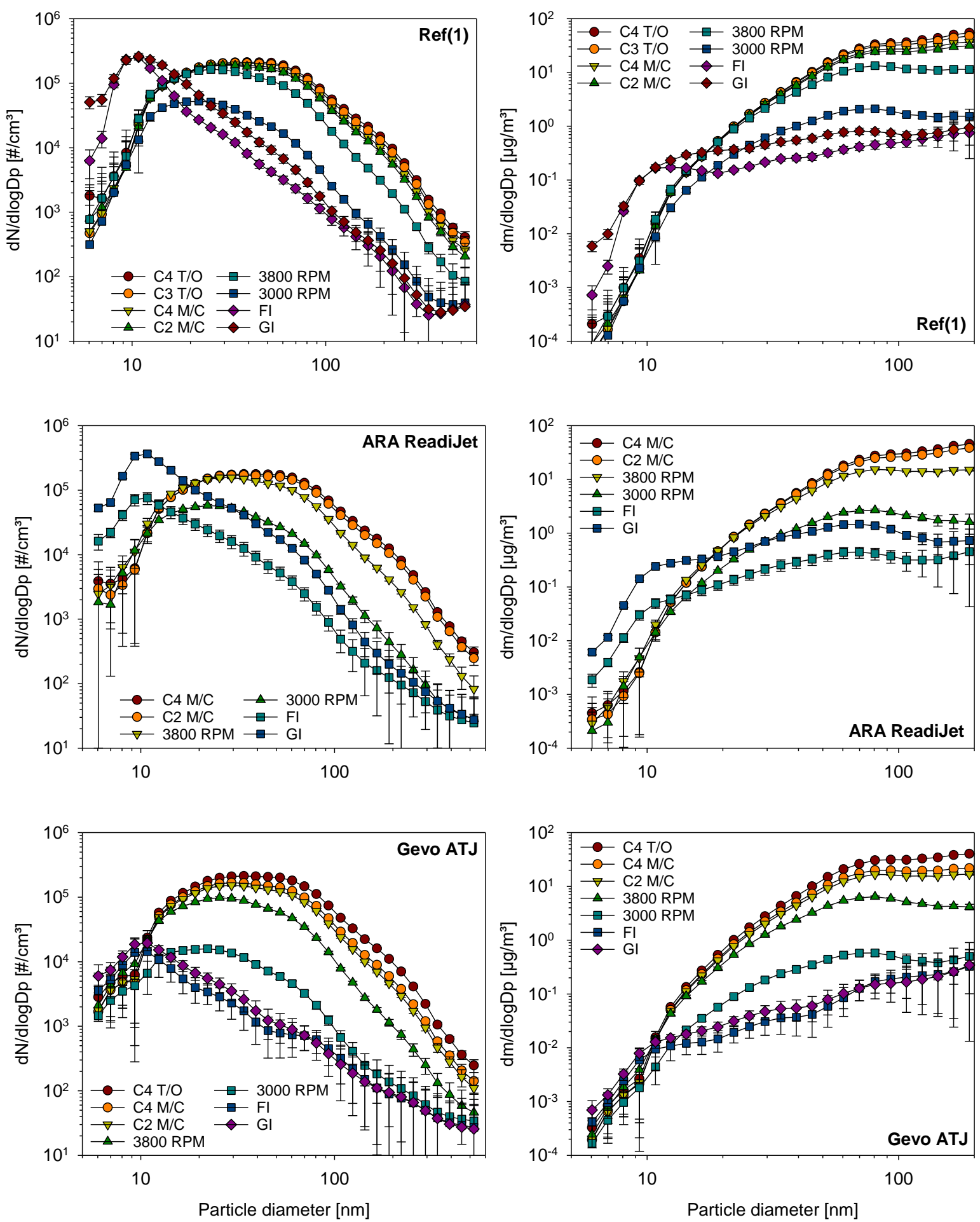

Figure 3: Particle number distributions (left, $5.6-560 \mathrm{~nm}$ ) and particle mass distributions (right, $5.6-200 \mathrm{~nm}$ ) for each fuel at different power settings (loss-corrected). 


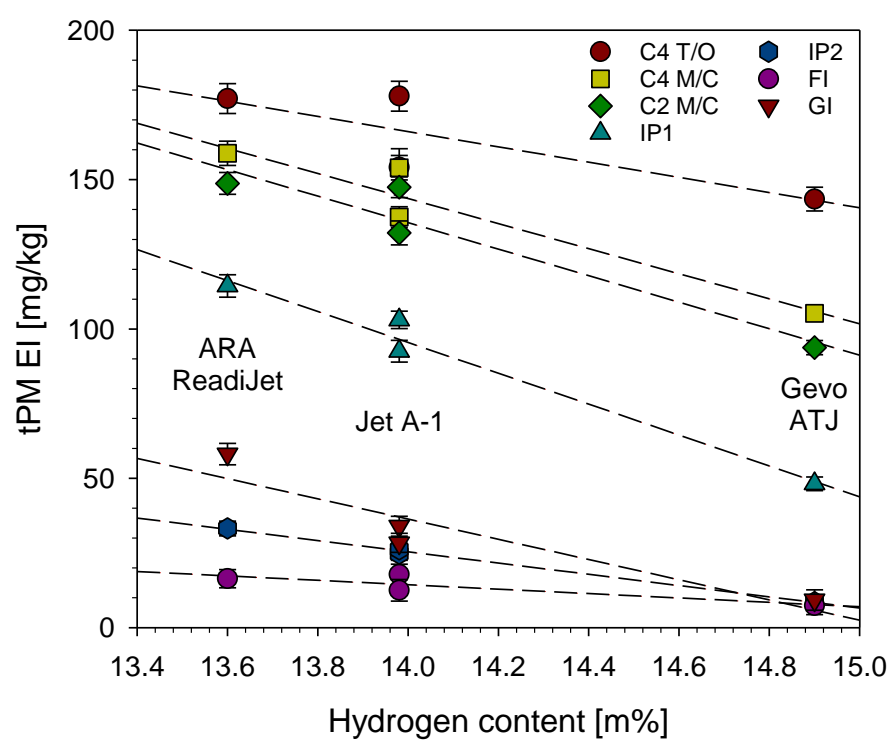

Figure 4: Correlation between particle mass emission index (EEPS) and hydrogen content (ASTM D7171) of the fuels. The dashed lines represent linear fits.

In contrast to the upper mentioned studies, our experiment does not strictly follow the analytical procedure described in AIR 6241 [21]. The experiment did not intend to study the emission performance of the applied engine, but focused on the effect of the different fuels. The Engine Exhaust Particle Sizer may show deviations to SMPS measurements in some exhaust measurements [28], but the comparable DMS500 has been successfully applied in aircraft measuring campaigns [29]. With regard to sampling, the probe was not installed near to the exit plane of the engine in order to obtain an aged aerosol, which can be compared to in-field studies. However, due to the flow tunnel following the engine in the test rig, the particle concentration should be in a similar range. The particle mass concentration at the exit plane can be estimated via different generic models for turboshaft engines. We applied the imFOX model [30] and the FOA3 model [31] to the reference kerosene runs (Figure SI4). The imFOX model considers the H-content of the fuel. According to the model using the values in Table 1 (ASTM D7171), the ARA Readijet should emit 50\% more particle mass compared to the reference fuel while the ATJ should show a reduction of $-60 \%$. Both values are in excellent agreement with the present findings (Figure 5). At low power settings, the models estimate a higher BC concentration, but the FOA3 model agrees well with our data at 
high power settings. These results are expected to be transferable to other test rig studies and in-field studies. However, the number of airport studies that report particle emission values for a CFM56-5C engine is limited. Moore et al. [14] report take-off emission values for two A340 aircrafts with CFM56-5C4 engines using an EEPS. The observed total particle number emission indices $\left(4.26 \cdot 10^{16} \# / \mathrm{kg}\right.$ and $\left.3.36 \cdot 10^{16} \# / \mathrm{kg}\right)$ are significantly higher than in this study. It might be possible that differences in the ambient conditions but also in the sulfur content of the fuels are responsible for this deviation but this assumption cannot be verified. The observed particle mass emission indices during take-off $(355.20 \mathrm{mg} / \mathrm{kg}$ and 282.32 $\mathrm{mg} / \mathrm{kg}$ ) are approx. twice as high as the test rig results of this study. This deviation might be caused by the assumption of the effective particle density in combination with the higher observed particle number. The comparison is further complicated by the fact that these values represent a transient process during acceleration of the aircraft which will be discussed below.

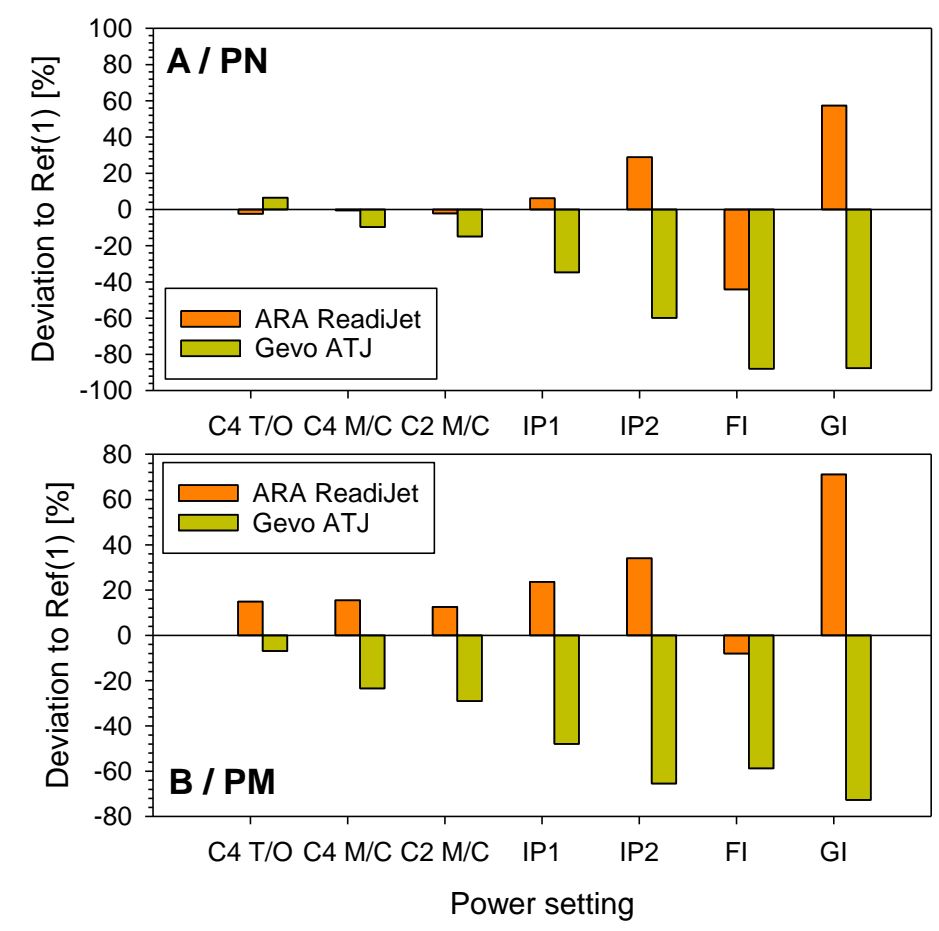

Figure 5: Deviation of particle number emission index $(A)$ and particle mass emission index (B) of the alternative jet fuels compared to $\operatorname{Ref}(1)$. 
Four experiments with non-steady operation were performed in the framework of this study with regular Jet A-1 (reference fuel). Two types of patterns were used for the experiment. The runs $A$ and $B$ should represent very rapid changes in thrust ( $5 \mathrm{~s}$ to $\sim 90 \%$ thrust) with two different "tailing"-behaviors in the decreasing phases (Figure 6). In contrast, the runs C and D represent slow thrust changes ( $\sim 30 \mathrm{~s}$ and $\sim 90 \mathrm{~s}$ to $\sim 90 \%$ thrust). It is important to note that these artificial patterns were not selected to represent real application conditions of the engine. Due to the longer operation, the runs $C$ and $D$ transferred a higher total impulse to the engine than the first two runs (Table 3). It further led to a "stretched" particle number concentration peak compared to the high peak values observed at rapid increase of speed. In order to quantitatively compare the four runs, sum values over each experimental run are derived for many parameters (Table 3) and normalized for the overall impulse produced by the engine. The total impulse is calculated via numerical integration of the measured engine thrust in the selected time interval. In case of the particles and combustion gases, a similar effect is achieved by numerical integration of the emission index. Note that the time resolution of the slowest measuring instrument $(\mathrm{FT}-\mathrm{IR})$ determines the time resolution to $5 \mathrm{~s}$ reducing the benefit of the EEPS high-time resolved recording. This time resolution is similar to the time to reach maximum thrust in the runs $A$ and $B$ (Table 3 ). The corresponding increase in particle number concentration was, nevertheless, determined at sufficient precision by the EEPS (see Figure 6) for both runs. The delay in the particle number concentration change and thrust settings change is caused by the dead time of the sampling system (approx. $7 \mathrm{~s}$ ). 


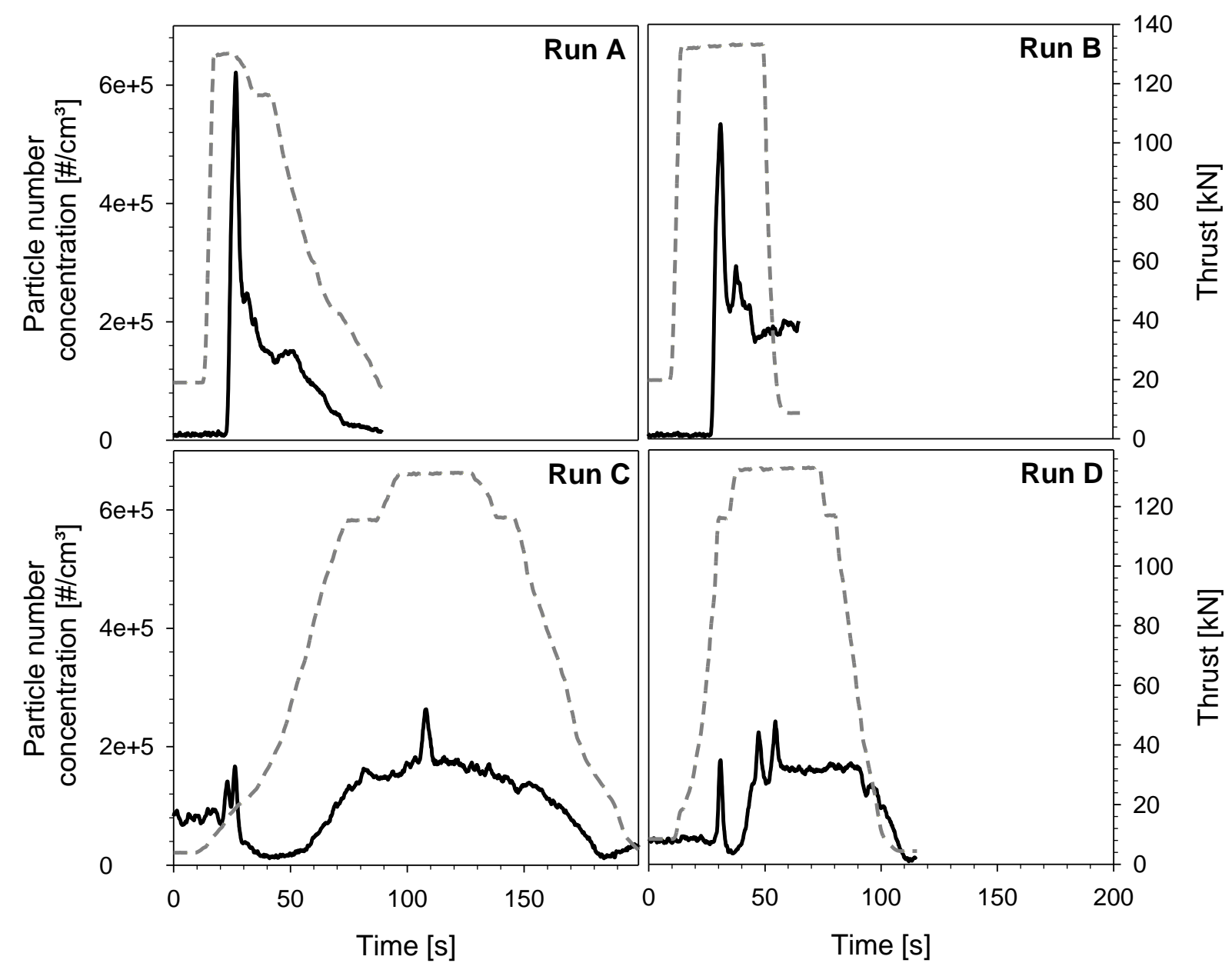

Figure 6: Particle number concentration $(5.6-560 \mathrm{~nm}, 10 \mathrm{~Hz})$ development (black line) at different acceleration conditions. The thrust (grey dashed line) is recorded at $2 \mathrm{~Hz}$.

In case of the nitrogen oxides emission (Table 3) no trend in the normalized emission could be observed when comparing the different runs. Due to the nearly linear increase of the nitrogen oxides emission with the combustion chamber inlet temperature (T3) and the thrust setting (Figure 1) it can be expected that the time at the highest power settings has the strongest impact on the overall emissions. This assumption is confirmed in the present case. The time at elevated power settings is rather similar for the experiments B-D (Table 3 ). In contrast, the normalized carbon monoxide emission seems to be lower for the runs $A$ and $B$ in comparison to the following runs. However, carbon monoxide emission mainly occurs at low power settings (Figure 1) and the initial conditions were slightly different. The runs $A$ and B had to start from approx. $13 \%$ thrust, while the runs C and D started from approx. $3 \%$ 
thrust. Since the impact of the lower power settings is not corrected by the normalization, the respective $\mathrm{CO}$ emissions are expected to be slightly higher. It must be noted, however, that the time resolution of the FT-IR was not sufficient (as mentioned above) and might have missed the peak emission at lower power settings. Nevertheless, the impact of the different acceleration patterns was low for the combustion gases.

Table 3: Summary of the operational and emission parameters of the engine at different acceleration conditions.

\begin{tabular}{|c|c|c|c|c|}
\hline & \multicolumn{2}{|c|}{ Fast acceleration } & \multicolumn{2}{|c|}{ Slow acceleration } \\
\hline & Run A & Run B & Run C & Run D \\
\hline \multicolumn{5}{|l|}{ Engine } \\
\hline Total impulse [kNs] & 6310 & 5686 & 14953 & 8681 \\
\hline Initial thrust [kN] ([\%]) & $20(13 \%)$ & $20(13 \%)$ & $4(3 \%)$ & $8(6 \%)$ \\
\hline Maximum thrust [kN] ([\%]) & $130(86 \%)$ & $133(88 \%)$ & $133(88 \%)$ & $133(88 \%)$ \\
\hline Time to max. thrust [s] & 5.5 & 5.5 & 88.0 & 27.5 \\
\hline Time at max. thrust [s] & 10 & 35 & 32 & 36 \\
\hline Total Duration [s] & 90 & 65 & 215 & 115 \\
\hline Fuel consumption [kg] & 65.8 & 63.5 & 158.7 & 95.1 \\
\hline \multicolumn{5}{|l|}{ Particle number (PN) } \\
\hline Total emitted PN $\left[10^{15} \#\right]$ & 10.86 & 9.42 & 18.86 & 11.77 \\
\hline Total PN / total impulse $\left[10^{15} \# /(\mathrm{Ns})\right]$ & 1.72 & 1.66 & 1.26 & 1.36 \\
\hline Estimated PN $\left[10^{15} \#\right]^{a)}$ & 6.52 & 4.51 & 17.47 & 9.46 \\
\hline \multicolumn{5}{|l|}{ Particle mass (PM) } \\
\hline Total emitted PM [g] & 13.6 & 12.4 & 21.1 & 13.8 \\
\hline Total PM / total impulse [g / (Ns)] & 2.1 & 2.2 & 1.4 & 1.6 \\
\hline Estimated PM [g] ${ }^{\text {a) }}$ & 7.4 & 6.1 & 20.0 & 11.6 \\
\hline \multicolumn{5}{|l|}{ Nitrogen oxides $\left(\mathrm{NO}_{\mathrm{x}}\right)$} \\
\hline Total emitted $\mathrm{NO}_{\mathrm{x}}[\mathrm{g}]$ & 905 & 1077 & 2669 & 1712 \\
\hline Total $\mathrm{NO}_{\mathrm{x}} /$ total impulse $[\mathrm{g} /(\mathrm{Ns})]$ & 143 & 189 & 178 & 197 \\
\hline \multicolumn{5}{|l|}{ Carbon monoxide (CO) } \\
\hline Total emitted CO [g] & 232 & 209 & 607 & 361 \\
\hline Total CO / total impulse [g / (Ns)] & 37 & 37 & 41 & 42 \\
\hline
\end{tabular}

a) estimated from emission indices at stationary conditions (Figure 2), see text for details

The normalized total particle number emission (Total PN / total impulse) feature approx. 30\% less particles in the slower runs $C$ and $D$ than the faster acceleration runs $A$ and $B$. This deviation - by percentage - is even larger, when the normalized particle mass emission is considered. The particle number emission tends to decrease with increasing time to reach maximum thrust. The same applies for the particle mass. The count median diameter rises 
from $\sim 15 \mathrm{~nm}$ at low power settings to $\sim 40 \mathrm{~nm}$ at the highest thrust in each experiment. The particle size distribution development was not significantly different within the four acceleration run experiments. This resulted in a good correlation between the total number of emitted particles and the total emitted particle mass. The difference in the particle emission is likely caused by the inertia of the system. Expressing the different acceleration runs as a series of pseudo-stationary processes on the basis of the results from the first experiment (Figure 2) is of particular interest.

In order to compare the stationary measurements and the acceleration runs, the timeresolved emission indices were calculated for each run using the known thrust condition, fuel flow and multi-linear regression of the particle emission indices shown in Figure 2. The result is given in Table 3 for particle number and mass. It can be observed that for both parameters, this approach underestimates the emission for run $A$ and $B$, while it estimates the values for the runs $C$ and $D$ in a far better manner. From these results it can be assumed that the "slower" thrust changes give the system enough time to adapt to the changing conditions and reach nearly stationary states. The observed correlation between stationary and transient measurements is currently limited for the tested engine type due to the limited number of experiments. The presented results demonstrate that transient processes can be described from stationary measurements to a sufficient extent. This matches well with the discussed correlation between the determined test-rig emission indices and field studies.

Note that the acceleration patterns used in this study do not reflect real application conditions and the acceleration during take-off can be influenced by the aircraft crew to a minor extend. This is important, since take-off acceleration is a security-relevant parameter and deviations from regular conditions may affect the safety of the aircraft [32].

\section{Conclusions and Outlook}

This test rig study demonstrated the successful application of a non-ASTM compliant jet fuel on a full-scale jet engine. The key operating parameter of the engine showed no deviation to the reference kerosene runs. The particle emission from both unblended alternative jet fuels 
followed the expected correlation with the hydrogen content of the fuels. The $\mathrm{CH}$ kerosene (ReadiJet) illustrates that alternative jet fuels are not necessarily associated with lower nonCO2 emissions. In contrast, the alcohol-to-jet type fuel represents the best achievable reduction in PM emission due to the total absence of aromatics. One future challenge is the identification of feasible blending components for designing a fuel with optimized particle emission properties that complies with current and future ASTM criteria. The reduction efficiency of such designed fuels has to be demonstrated under real application conditions. Here, the impact of aircrafts on the local air quality of airports is of particular interest. Ground emissions are a mixture of constant (taxi) and transient processes (take-off). The comparison between the transient and steady-state emission patterns in this study showed for this engine that transient processes could be described as a set of pseudo-stationary processes. However, if there is a sudden change in thrust setting (e.g. $5 \mathrm{~s}$ to $\sim 90 \%$ thrust) the applied analytics reaches its limits. Due to the limitation on one engine and a small amount of acceleration patterns, the current test rig experiment must be linked with field studies and modeling studies to gain more insight into the relevance of transient processes for the particle emission at airports.

\section{Acknowledgments}

This study has been funded by the German Federal Ministry of Economic Affairs and Energy in the framework of the project "airegEM - Emission properties of alternative jet fuels" (FKZ 20T1310B).

\section{References}

[1] Lee DS, Pitari G, Grewe V, Gierens K, Penner JE, Petzold A, et al. Transport impacts on atmosphere and climate: Aviation. Atmospheric Environment 2010;44(37):4678734.

[2] Targino AC, Machado BL, Krecl P. Concentrations and personal exposure to black carbon particles at airports and on commercial flights. Transport Res Part DTransport Environ 2017;52:128-38.

[3] Moore RH, Thornhill KL, Weinzierl B, Sauer D, D'Ascoli E, Kim J, et al. Biofuel blending reduces particle emissions from aircraft engines at cruise conditions. Nature 2017;543(7645):411-5.

[4] Grewe V, Dahlmann K, Flink J, Frömming C, Ghosh R, Gierens KM, et al. Mitigating the Climate Impact from Aviation: Achievements and Results of the DLR WeCare Project. Aerospace 2017;4(3):1-50. 
[5] Lobo P, Christie S, Khandelwal B, Blakey SG, Raper DW. Evaluation of Non-volatile Particulate Matter Emission Characteristics of an Aircraft Auxiliary Power Unit with Varying Alternative Jet Fuel Blend Ratios. Energy \& Fuels 2015;29(11):7705-11.

[6] Moore RH, Shook M, Beyersdorf A, Corr C, Herndon S, Knighton WB, et al. Influence of Jet Fuel Composition on Aircraft Engine Emissions: A Synthesis of Aerosol Emissions Data from the NASA APEX, AAFEX, and ACCESS Missions. Energy \& Fuels 2015;29(4):2591-600.

[7] Schripp T, Anderson B, Crosbie EC, Moore RH, Herrmann F, Osswald P, et al. Impact of Alternative Jet Fuels on Engine Exhaust Composition During the 2015 ECLIF Ground-Based Measurements Campaign. Environmental Science \& Technology 2018;52(8):4969-78.

[8] Brem BT, Durdina L, Siegeris F, Beyerle P, Bruderer K, Rindlisbacher T, et al. Effects of Fuel Aromatic Content on Nonvolatile Particulate Emissions of an In-Production Aircraft Gas Turbine. Environmental Science \& Technology 2015;49(22):13149-57.

[9] Corporan E, Edwards T, Shafer L, DeWitt MJ, Klingshirn C, Zabarnick S, et al. Chemical, Thermal Stability, Seal Swell, and Emissions Studies of Alternative Jet Fuels. Energy \& Fuels 2011;25(3):955-66.

[10] Beyersdorf AJ, Timko MT, Ziemba LD, Bulzan D, Corporan E, Herndon SC, et al. Reductions in aircraft particulate emissions due to the use of Fischer-Tropsch fuels. Atmospheric Chemistry and Physics 2014;14(1):11-23.

[11] Lobo P, Hagen DE, Whitefield PD. Comparison of PM Emissions from a Commercial Jet Engine Burning Conventional, Biomass, and Fischer-Tropsch Fuels.

Environmental Science \& Technology 2011;45(24):10744-9.

[12] Zheng LK, Ling CX, Ubogu EA, Cronly J, Ahmed I, Zhang Y, et al. Effects of Alternative Fuel Properties on Particulate Produced in a Gas Turbine Combustor. Energy \& Fuels 2018;32(9):9883-97.

[13] Lobo P, Condevaux J, Yu ZH, Kuhlmann J, Hagen DE, Miake-Lye RC, et al. Demonstration of a Regulatory Method for Aircraft Engine Nonvolatile PM Emissions Measurements with Conventional and Isoparaffinic Kerosene fuels. Energy \& Fuels 2016;30(9):7770-7.

[14] Moore RH, Shook MA, Ziemba LD, DiGangi JP, Winstead EL, Rauch B, et al. Data Descriptor: Take-off engine particle emission indices for in-service aircraft at Los Angeles International Airport. Sci Data 2017;4:15.

[15] ICAO. ICAO Annex 16: Environmental Protection, Volume II -- Aircraft Engine Emissions. Quebec, Canada: ICAO; 2008.

[16] Zschocke A, Scheuermann S, Ortner J. High Biofuel Blends in Aviation (HBBA). 2012.

[17] Johnson TJ, Olfert JS, Symonds JPR, Johnson M, Rindlisbacher T, Swanson JJ, et al. Effective Density and Mass-Mobility Exponent of Aircraft Turbine Particulate Matter. J Propul Power 2015;31(2):573-82.

[18] Kulkarni P, Baron PA, Willeke K. Aerosol Measurement - Principles, Techniques and Applications. Hoboken, New Jersey: John Wiley \& Sons; 2011.

[19] ICAO. Airport Air Quality Manual (Doc. 9889). Quebec, Canada; 2011.

[20] EASA. ICAO Aircraft Engine Emissions Databank (www.easa.europa.eu, 01.06.2017). 2017.

[21] SAE AIR 6241. Procedure for the Continuous Sampling and Measurement of NonVolatile Particle Emissions from Aircraft Turbine Engines. Berlin: Beuth Verlag; 2013.

[22] Lefebvre AH, Ballal DR. Chapter 6: Fuel Injection. Gas Turbine Combustion Alternative Fuels and Emissions. Boca Raton, FL: CRC Press; 2010.

[23] Cain J, DeWitt MJ, Blunck D, Corporan E, Striebich R, Anneken D, et al. Characterization of Gaseous and Particulate Emissions From a Turboshaft Engine Burning Conventional, Alternative, and Surrogate Fuels. Energy \& Fuels 2013;27(4):2290-302.

[24] Timko MT, Onasch TB, Northway MJ, Jayne JT, Canagaratna MR, Herndon SC, et al. Gas Turbine Engine Emissions-Part II: Chemical Properties of Particulate Matter. J Eng Gas Turbines Power-Trans ASME 2010;132(6):15. 
[25] Oßwald P, Whitside R, Schäffer J, Köhler M. An experimental flow reactor study of the combustion kinetics of terpenoid jet fuel compounds: Farnesane, p-menthane and p-cymene. Fuel 2017;187:43-50.

[26] ASTM D7566-17a. Standard Specification for Aviation Turbine Fuel Containing Synthesized Hydrocarbons. 2017.

[27] Chan TW, Chishty WA, Canteenwalla P, Buote D, Davison CR. Characterization of Emissions From the Use of Alternative Aviation Fuels. J Eng Gas Turbines PowerTrans ASME 2016;138(1):9.

[28] Wang XL, Grose MA, Caldow R, Osmondson BL, Swanson JJ, Chow JC, et al. Improvement of Engine Exhaust Particle Sizer (EEPS) size distribution measurement - II. Engine exhaust particles. Journal of Aerosol Science 2016;92:83-94.

[29] Hagen DE, Lobo P, Whitefield PD, Trueblood MB, Alofs DJ, Schmid O. Performance Evaluation of a Fast Mobility-Based Particle Spectrometer for Aircraft Exhaust. J Propul Power 2009;25(3):628-34.

[30] Abrahamson JP, Zelina J, Andac MG, Vander Wal RL. Predictive Model Development for Aviation Black Carbon Mass Emissions from Alternative and Conventional Fuels at Ground and Cruise. Environmental Science \& Technology 2016;50(21):12048-55.

[31] Wayson RL, Fleming GG, lovinelli R. Methodology to Estimate Particulate Matter Emissions from Certified Commercial Aircraft Engines. Journal of the Air \& Waste Management Association 2009;59(1):91-100.

[32] AAIB. Aircraft Accident Report 2/2018 - Report on the serious incident to Boeing 73786J, C-FWGH Belfast International Airport on 21 July 2017. London: Air Accidents Investigation Branch; 2018. 